\title{
Dietary neutral lipid level and source in Senegalese sole (Solea senegalensis) larvae: Effect on growth, lipid metabolism and digestive capacity
}

\author{
S. Morais ${ }^{\text {a,*}}$, M.J. Caballero ${ }^{\text {b }}$, L.E.C. Conceição ${ }^{a}$, M.S. Izquierdo ${ }^{\text {b }}$, M.T. Dinis ${ }^{a}$

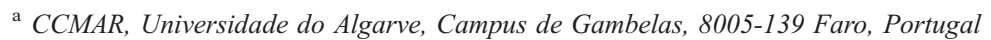 \\ ${ }^{\mathrm{b}}$ Grupo de Investigación en Acuicultura, ULPGC and ICCM, P.O. Box 56, 35200, Telde, Las Palmas de Gran Canaria, Canary Islands, Spain
}

Received 30 September 2005; received in revised form 30 December 2005; accepted 16 January 2006

Available online 6 March 2006

\begin{abstract}
Contrary to larval essential fatty acid (EFA) requirements, the effect of dietary neutral lipid supply has been little investigated in marine fish larvae. The present work investigates the effect of feeding Senegalese sole larvae on Artemia enriched with higher or lower doses of lipid emulsion. Two lipid sources - soybean oil and fish oil — were compared. From 16 days after hatching (DAH) onwards, larvae were fed one of four experimental treatments: Artemia enriched on a high or low dose of soybean oil emulsion (HS and LS) or Artemia enriched on a high or low dose of fish oil emulsion (HF and LF). In terms of growth, the dietary lipid level did not have a significant effect while the soybean oil treatments induced a lower growth than the fish oil-enriched Artemia. The fatty acid (FA) composition of the larvae closely reflected the dietary quantitative and qualitative FA profile. Only slight dietary effects were noted in the activity of trypsin, lipase and alkaline phosphatase. A higher amount of lipid droplets was noticeable in the posterior intestine epithelia and in the hepatocytes of larvae fed Artemia enriched with higher lipid doses, while LS-Artemia induced the lower lipid accumulation on the basal zone of the enterocytes, in accordance with the lowest total lipid level measured in this treatment. These results suggest an important effect of dietary total lipid level on lipid accumulation in the enterocytes and on FA absorption. At 33 DAH a tube feeding trial was conducted with ${ }^{14} \mathrm{C}$-labelled oleic acid (OA) or triolein (TRI), showing that the lower accumulation of lipid droplets in the larvae fed LS was associated with a significantly higher absorption and retention in the gut and body tissues of the TRI label. For OA no significant differences between treatments were found. TRI label was considerably more evacuated than OA, indicating that sole larvae may have a lower capacity to incorporate a triacylglycerol, which needs to be digested. Finally, OA appears to be preferentially utilized for energy production, accumulating more in larval tissues when absorbed in higher amounts.
\end{abstract}

(C) 2006 Elsevier Inc. All rights reserved.

Keywords: Triacylglycerol level; Artemia enrichment; Lipid absorption; Lipid vacuoles; Enterocytes; Digestive enzymes; Oleic acid; Triolein

\section{Introduction}

Lipids are important components in diets for larval fish species, given their central role as a source of energy and essential fatty acids (EFA) (Rainuzzo et al., 1997; Sargent et al., 1997, 1999). Therefore, in the last decades, a large amount of research effort has been directed towards the development of

Abbreviations: ARA, arachidonic acid (20:4n-6); DAH, days after hatching; DHA, docosahexaenoic acid (22:6n-3); EFA, essential fatty acids; EPA, eicosapentaenoic acid (20:5n-3); FA, fatty acids; FAME, fatty acid methyl esters; HUFA, highly unsaturated fatty acids ( $\geq 20$ carbon atoms and $\geq 4$ double bonds); MUFA, monounsaturated fatty acids; PUFA, polyunsaturated fatty acids ( $\geq 2$ double bonds); SFA, saturated fatty acids.

* Corresponding author. Tel.: +351 289800 100; fax: +351 289818353.

E-mail address: smorais@ualg.pt (S. Morais). lipid enrichment products and strategies, in order to raise the EFA content, particularly of the n-3 highly unsaturated fatty acids (HUFA; $\geq 20$ carbon atoms and $\geq 4$ double bonds), of the nutritionally deficient live preys used in marine larviculture (Rodríguez et al., 1996; Rainuzzo et al., 1997; Han et al., 2000). However, excessive dietary lipid contents or unbalances in lipid class composition found occasionally in enriched live preys have been suggested to affect fatty acid (FA) digestion and absorption (Salhi et al., 1995, 1997, 1999; Diaz et al., 1997) and have been related to poor larval growth and performance in several species (Kjørsvik et al., 1991; Hoehne, 1999; Pousão-Ferreira et al., 1999; Izquierdo et al., 2000; Olsen et al., 2000a). In larvae of Senegalese sole (Solea senegalensis Kaup 1858), the long term feeding of a higher neutral lipid Artemia resulted in reduced growth, higher lipid droplet accumulation within the gut 
enterocytes (mostly in the basal zone) and lower capacity of larvae to absorb dietary FA (Morais et al., 2005a,b). Since in these previous studies the Artemia neutral lipid content was increased by enrichment with a soybean oil emulsion, rich in linoleic acid (18:2n-6), while the low lipid Artemia was nonenriched, these live preys not only differed in their lipid content but also in their FA composition. Moreover, despite both types of Artemia being deficient in HUFA, the enrichment with soybean oil may have caused a dilution of the EFA naturally present in Artemia (mostly eicosapentaenoic acid - EPA, 20:5n-3; and arachidonic acid - ARA, 20:4n-6), possibly contributing to the observed changes in growth. In addition, lipid absorption could also have been affected by the change in Artemia FA profile, since it has been shown in carnivorous juvenile and adult fish that the inclusion of plant-derived oils may result in a reduction of the transport rate across the gut epithelia and thus in the accumulation of lipid droplets in the enterocytes, possibly leading to tissue damage and compromised gut integrity (Olsen et al., 1999, 2000b, 2003; Caballero et al., 2002, 2003). Besides, dietary FA profile may influence not only the composition and morphology of the intestinal cells but also the physiological mechanisms involved in intestinal lipid metabolism and transport (Sire and Vernier, 1981; Caballero et al., 2002, 2003).

Having this in mind, the present study was conducted in order to clarify the importance of total neutral lipid and FA contents in Artemia, on dietary lipid absorption and growth performance of fish larvae. Hence, this study aimed to determine the effect of feeding Senegalese sole larvae with Artemia enriched with two different types of oil (soybean and fish oil), at two inclusion levels, on larval growth, on the morphology of the gut mucosa and on digestive and absorptive processes such as enzyme activity, FA absorption and metabolism.

\section{Materials and methods}

\subsection{Larval rearing and experimental diets}

Larvae were obtained from IPIMAR-CRIPSul (Olhão, Portugal) at 14 days after hatching (DAH), with an average wet mass of $3.73 \pm 0.17 \mathrm{mg}(n=5,20$ pooled larvae). Until this age they had been fed Artemia enriched in a mixture of microalgae Nannochloropsis sp. and Isochrysis sp (50:50, on a volume basis). At this time the larvae had already settled and were transferred to a recirculation system of 12 three L flat bottom trays, which were stocked with 200 larvae each. During two acclimation days the larvae in all the trays were fed Artemia enriched for $12 \mathrm{~h}$, at 250 nauplii $\mathrm{mL}^{-1}$, with a mixture of Easy DHA Selco (INVE Aquaculture NV, Dendermonde, Belgium; two doses, at 0 and $9 \mathrm{~h}$, according to manufacturer's instructions) and Microfeed (EWOS, Bathgate, Scotland; $0.4 \mathrm{~g} \mathrm{~L}^{-1}$ in the same two doses).

From 16 DAH onwards the larvae were fed one of four experimental treatments, in triplicate trays: Artemia enriched on a high dose of soybean oil emulsion (HS), Artemia enriched on a low dose of soybean oil emulsion (LS), Artemia enriched on a high dose of fish oil emulsion (HF) and Artemia enriched on a low dose of fish oil emulsion (LF). The enrichment oil emul- sions were prepared by mixing (per $100 \mathrm{~g}$ of emulsion): $86 \mathrm{~g}$ of commercial soybean oil (OliSoja, Sovena, Portugal) or fish oil (mostly sardine oil; Sorgal, Ovar, Portugal), $5 \mathrm{~g}$ of soybean lecithin (Sorgal), $3 \mathrm{~g}$ of Tween 80 (Sigma-Aldrich, St. Louis, MO, USA), $2 \mathrm{~g}$ of alginic acid (Sigma-Aldrich), $2 \mathrm{~g}$ of a vitamin mixture containing $35 \%$ vitamin $\mathrm{C}$ (Sorgal) and $2 \mathrm{~g}$ of another mixture including 50\% vitamin $\mathrm{E}$ (Sorgal). Non-decapsulated Artemia cysts (EG 480, INVE Aquaculture NV) were hatched according to Van Stappen (1996) and the enrichments were prepared by blending the emulsions with water $(1 \mathrm{~g}$ emulsion : 100-200g water) in a high speed blender and were conducted during $16 \mathrm{~h}$ at a density of 150 instar II nauplii $\mathrm{mL}^{-1}$ of seawater $\left(35 \mathrm{~g} \mathrm{~L}^{-1}\right)$, at $28-30{ }^{\circ} \mathrm{C}$ and with strong aeration. In the high lipid enrichments (HS and HF), $0.6 \mathrm{~g} \mathrm{~L}^{-1}$ were added in two doses $\left(0.4 \mathrm{~g} \mathrm{~L}^{-1}\right.$ at $0 \mathrm{~h}$ and $0.2 \mathrm{~g} \mathrm{~L}^{-1}$ at $8 \mathrm{~h}$ ), while a single dose of $0.04 \mathrm{~g} \mathrm{~L}^{-1}$ was added at the start of the enrichment in the low lipid treatments (LS and LF). A single batch of enriched Artemia from each treatment was produced and was kept frozen for the duration of the experiment. Samples of Artemia from each treatment were collected in three eppendorfs and into liquid nitrogen, for the determination of total lipid and FA composition. Larvae were fed frozen enriched Artemia (after thawing in seawater), providing an inert feed for the fish (Dinis et al., 1999), in excess to satiation, three times daily. Photoperiod was $12 \mathrm{~L}: 12 \mathrm{D}$, salinity was kept at $33 \mathrm{~g} \mathrm{~L}^{-1}$, temperature varied between 20.5 and $22{ }^{\circ} \mathrm{C}$ and oxygen level was maintained at $93-97 \%$.

\subsection{Sampling}

Larvae were collected at the start of the experiment $(n=5,20$ pooled larvae each) and were stored in liquid nitrogen, for later FA analysis. At $23 \mathrm{DAH}$, after 7 days of feeding on the experimental diets, 20 larvae were collected from each tray, washed in distilled water, frozen and later freeze-dried in a Savant VLP120 ValuPump (Savant Instruments Inc., Holbrook, NY, USA), for the determination of individual dry weight (DW). Close to the end of the experiment, at $32 \mathrm{DAH}$, larvae were sampled again for the determination of DW and protein content $\left(20\right.$ larvae tray $\left.{ }^{-1}\right)$, optical histological analysis (20 larvae tray ${ }^{-1}$, fixed in $10 \%$ buffered formalin-calcium) and total lipid and FA analysis (20 larvae tray ${ }^{-1}$, stored in liquid nitrogen until analysis). Sampling for enzyme analysis was conducted at 34 DAH (20 larvae tray ${ }^{-1}$, washed in distilled water and stored in liquid nitrogen).

\subsection{Total protein, total lipid and fatty acid analysis}

The larvae used in the measurement of individual DW at 32 DAH were later pooled, re-hydrated and homogenised (Ultra Turrax T25, IKA Labortechnik, Staufen, Germany), followed by freeze-drying. Each freeze-dried sample (one per tray) was then divided in triplicate aliquots on which total protein content was determined according to a method modified from Lowry (Rutter, 1967). The same method was used to determine the total protein of the experimental diets. Lipids were extracted with a chloroform:methanol $(2: 1, \mathrm{v}: \mathrm{v})$ mixture, as described by Folch et al. (1957). The fatty acid methyl esters (FAME) were 
Table 1

Total protein and lipid content (\% of dry weight, DW) of the experimental diets and of the larvae, at $32 \mathrm{DAH}$. Values for the Artemia correspond to a single enrichment batch, while values for 32 DAH larvae are means $(n=3) \pm$ S.D.

\begin{tabular}{lll}
\hline Treatment & Total protein $(\% \mathrm{DW})$ & Total lipid $(\% \mathrm{DW})$ \\
\hline Enriched Artemia & & \\
HS & 32.8 & 23.2 \\
LS & 28.7 & 20.0 \\
HF & 34.9 & 25.2 \\
LF & 33.6 & 23.0 \\
& & \\
Larvae (32 DAH) & & \\
HS & $55.2 \pm 2.1$ & $27.0 \pm 1.3$ \\
LS & $55.8 \pm 0.2$ & $27.8 \pm 1.6$ \\
HF & $53.8 \pm 0.7$ & $28.8 \pm 0.9$ \\
LF & $57.3 \pm 0.4$ & $25.4 \pm 1.3$ \\
\hline
\end{tabular}

obtained by transesterification with $1 \%$ sulphuric acid in methanol and were purified by adsorption chromatography on $\mathrm{NH} 2$ sep-pack cartridges (Waters, S.A., Milford, MA, USA), as decribed by Fox (1990), and separated and quantified by gasliquid chromatography following the conditions described by Izquierdo et al. (1990). FAME were identified by comparison to external standards.

\subsection{Enzyme analysis}

The larvae (20 per replicate tray) that were kept in liquid nitrogen were defrosted on ice and their digestive tracts were dissected and homogenized (Ultra Turrax T25) in $1.5 \mathrm{~mL}$ of ice cold distilled water. The homogenate was used immediately for the determination of trypsin activity and was kept frozen $(-20$ ${ }^{\circ} \mathrm{C}$ ) until the remaining enzymatic determinations that were performed for alkaline phosphatase and lipase activities. Trypsin activity was assayed using BAPNA (Na-benzoyl-DL-arginine$p$-nitroanilide) (Sigma-Aldrich) as substrate (Tseng et al., 1982), while the activity of alkaline phosphatase was measured following the method of Bessey et al. (1946), using as subtrate $p$-nitrophenylphosphate (pNPP) (Sigma-Aldrich). Lipase activity was assayed according to a spectrophotometric method slightly modified from Iijima et al. (1998), using as substrate $p$ nitrophenyl myristate (Sigma-Aldrich) (Morais et al., 2004a). Enzyme specific activities were expressed as $\mu$ moles of substrate hydrolyzed per minute, per $\mathrm{mg}$ of protein (i.e., $\mathrm{U} \mathrm{mg}$ protein ${ }^{-1}$ ) at $25^{\circ} \mathrm{C}$ for trypsin, $37^{\circ} \mathrm{C}$ for alkaline phosphatase and $30^{\circ} \mathrm{C}$ for lipase. Enzyme activities were also expressed as segmental activities, i.e., total activity per larval segment (digestive tract). Protein was determined by the Bradford procedure (Bradford, 1976).

\subsection{Histological analysis}

To examine the histological appearance of the gut and liver of 32 DAH larvae, 10 larvae per tray fixed in $10 \%$ buffered formalin-calcium were dehydrated in a graded ethanol series and embedded in paraffin. Serial $4 \mu \mathrm{m}$ sections were stained with haematoxylin and eosin ( $\mathrm{H}$ and E) (Martoja and MartojaPierson, 1970) and examined under light microscopy. Evaluation of histological changes (amount of lipid vacuoles) in gut and liver was carried out using a four-graded examination scheme: $0=$ not observed; $1=$ scarce; $2=$ moderate $3=$ numerous.

\subsection{Tube feeding trial}

A tube feeding trial was conducted at $33 \mathrm{DAH}$, using the methodology and experimental setup described by Rønnestad et al. (2001) and Morais et al. (2005a). This method allows

Table 2

Fatty acid composition (g/100g fatty acids) of the enriched Artemia

\begin{tabular}{|c|c|c|c|c|}
\hline & HS & LS & $\mathrm{HF}$ & LF \\
\hline $14: 0$ & 0.56 & 0.71 & 1.60 & 1.16 \\
\hline $14: 1 n-5$ & 0.55 & 0.66 & 0.63 & 0.75 \\
\hline $14: 1 n-7$ & 0.17 & 0.26 & 0.29 & 0.25 \\
\hline $15: 0$ & 0.14 & 0.15 & 0.16 & 0.18 \\
\hline $15: 1 \mathrm{n}-5$ & 0.45 & 0.55 & 0.50 & 0.60 \\
\hline 16:0iso & 0.05 & 0.08 & 0.07 & 0.08 \\
\hline $16: 0$ & 13.85 & 18.10 & 14.02 & 12.49 \\
\hline $16: 1 n-9$ & 0.65 & 0.43 & 0.27 & 0.37 \\
\hline $16: 1 n-7$ & 1.99 & 2.27 & 4.46 & 3.71 \\
\hline Me 16:0 & 0.04 & 0.05 & 0.08 & 0.07 \\
\hline $16: 1 n-5$ & 0.49 & 0.73 & 0.56 & 0.62 \\
\hline $16: 2 n-6$ & 1.23 & 1.27 & 1.01 & 1.23 \\
\hline $17: 0$ & 0.06 & 0.11 & 0.58 & 0.40 \\
\hline $16: 2 n-4$ & 0.71 & 1.10 & 0.74 & 0.72 \\
\hline $16: 3 n-4$ & 0.54 & 0.62 & 0.73 & 0.77 \\
\hline $16: 3 n-3$ & 0.36 & 0.38 & 0.37 & 0.44 \\
\hline $16: 4 n-3$ & 0.16 & 0.18 & 0.19 & 0.22 \\
\hline $16: 4 n-1$ & 0.00 & 0.04 & 0.08 & 0.02 \\
\hline 18:0 & 8.37 & 11.18 & 6.01 & 6.02 \\
\hline $18: 1 n-9$ & 19.88 & 17.62 & 18.45 & 18.85 \\
\hline $18: 1 \mathrm{n}-7$ & 6.27 & 7.21 & 7.19 & 7.79 \\
\hline $18: 1 n-5$ & 0.08 & 0.09 & 0.13 & 0.12 \\
\hline $18: 2 n-9$ & 0.34 & 0.41 & 0.37 & 0.45 \\
\hline $18: 2 n-6$ & 19.12 & 9.40 & 4.67 & 5.40 \\
\hline $18: 2 n-4$ & 0.10 & 0.06 & 0.00 & 0.09 \\
\hline $18: 3 n-6$ & 0.36 & 0.44 & 0.43 & 0.48 \\
\hline $18: 3 n-4$ & 0.00 & 0.00 & 0.00 & 0.09 \\
\hline $18: 3 n-3$ & 17.15 & 18.35 & 17.35 & 21.54 \\
\hline $18: 4 n-3$ & 2.01 & 2.30 & 2.32 & 2.67 \\
\hline $18: 4 n-1$ & 0.00 & 0.00 & 0.06 & 0.00 \\
\hline 20:0 & 0.26 & 0.33 & 0.20 & 0.20 \\
\hline $20: 1 n-9$ & 0.45 & 0.46 & 0.20 & 0.02 \\
\hline $20: 1 n-7$ & 0.08 & 0.10 & 1.58 & 1.04 \\
\hline $20: 2 n-9$ & 0.03 & 0.00 & 0.05 & 0.05 \\
\hline $20: 2 n-6$ & 0.27 & 0.26 & 0.23 & 0.24 \\
\hline $20: 3$ & 0.00 & 0.09 & 0.10 & 0.00 \\
\hline $20: 4 n-6$ & 0.56 & 0.73 & 0.97 & 0.98 \\
\hline $20: 3 n-3$ & 0.44 & 0.50 & 0.48 & 0.58 \\
\hline $20: 4 n-3$ & 0.36 & 0.41 & 0.64 & 0.60 \\
\hline $20: 5 n-3$ & 1.48 & 1.81 & 6.82 & 5.47 \\
\hline $22: 1 n-11$ & 0.00 & 0.00 & 1.53 & 1.08 \\
\hline $22: 1 n-9$ & 0.29 & 0.45 & 0.18 & 0.15 \\
\hline $22: 4 n-6$ & 0.00 & 0.00 & 0.00 & 0.05 \\
\hline $22: 5 n-3$ & 0.00 & 0.15 & 0.73 & 0.40 \\
\hline $22: 6 n-3$ & 0.00 & 0.00 & 2.98 & 1.59 \\
\hline \multicolumn{5}{|l|}{ Totals } \\
\hline SFA & 23.34 & 30.71 & 22.71 & 20.60 \\
\hline MUFA & 31.35 & 30.81 & 35.96 & 35.34 \\
\hline PUFA & 45.22 & 38.48 & 41.32 & 44.06 \\
\hline HUFA & 2.40 & 3.10 & 12.14 & 9.09 \\
\hline n-3 PUFA & 21.97 & 24.07 & 31.87 & 33.51 \\
\hline n-6 PUFA & 21.54 & 12.09 & 7.32 & 8.37 \\
\hline$n-3 / n-6$ & 1.02 & 1.99 & 4.35 & 4.01 \\
\hline
\end{tabular}


following the metabolic fate of a tracer nutrient into the following compartments: retention in body and gut, catabolism $\left(\mathrm{CO}_{2}\right.$ trap) and evacuation. Larvae from each dietary treatment were tube fed a mixture of either ${ }^{14} \mathrm{C}$-radiolabelled glycerol tri $\left[1-{ }^{14} \mathrm{C}\right]$ oleate (or triolein, TRI; Amersham Pharmacia Biotech UK Limited, $3.7 \mathrm{MBq} \mathrm{mL}^{-1}$ ) or $\left[1-{ }^{14} \mathrm{C}\right]$ oleic acid (OA, 18:1n-9; Amersham Pharmacia Biotech UK Limited, Little Chalfont, Bucks, UK; 3.7 $\mathrm{MBq} \mathrm{mL}^{-1}$ ) and the absorption and metabolism of these labels were examined after an incubation period of $24 \mathrm{~h}$. The tube feeding mixtures were prepared by adding the labels to "cold" purified triolein (VWR Prolabo, Fontenay-sous-Bois, France), to obtain a specific activity of $222 \mathrm{dpm} \mathrm{nL}{ }^{-1}$ mixture and, after flushing with nitrogen $\left(\mathrm{N}_{2}\right)$ to evaporate all traces of solvents, the solutions were stored at $-20{ }^{\circ} \mathrm{C}$. On the day before the trial, $30 \mathrm{~min}$ after the last meal, 10 larvae were removed from each triplicate tray and pooled in smaller trays (two trays per treatment, one for tube feeding TRI and another for OA, containing a total of 15 larvae each). These trays were transported to the radioisotope experimental room, where the larvae were acclimated and kept unfed overnight. Temperature and salinity were maintained at $22{ }^{\circ} \mathrm{C}$ and $35 \mathrm{~g} \mathrm{~L}^{-1}$, respectively, and the trial was conducted under continuous illumination. Thirty minutes before tube feeding ca. 15,000 Artemia metanauplii of the enrichment being tested were added to each tray and the larvae were allowed to feed for $30 \mathrm{~min}$. Six larvae from each treatment were tube fed $46 \mathrm{~nL}$ of the radiolabel mixture (in two microinjections of $23 \mathrm{~nL}$ ). After $24 \mathrm{~h}$, each larva was removed from the incubation setup, rinsed in clean saltwater and the gut was separated from the remaining body by dissection. Both compartments were transferred separately to $6 \mathrm{~mL}$ scintillation vials (Sarstedt, Rio de Mouro, Portugal), and were solubilised in $200 \mu \mathrm{L}$ of $30 \% \mathrm{w} / \mathrm{v}$ hydrogen peroxide (SigmaAldrich) at $60{ }^{\circ} \mathrm{C}$ for $24 \mathrm{~h}$. After cooling, $4 \mathrm{~mL}$ of scintillation cocktail (Ultima Gold XR, Packard Bioscience, Monza, Italy) were added to each $6 \mathrm{~mL}$ vial. The $20 \mathrm{~mL}$ scintillation vials (Sigma-Aldrich) with $8 \mathrm{~mL}$ of incubation seawater (water compartment, containing the evacuated label) and the $20 \mathrm{~mL}$ vials containing $5 \mathrm{~mL}$ of $\mathrm{KOH} 0.5 \mathrm{M}$ that had been gradually acidified by the addition of $1 \mathrm{~mL}$ of hydrochloric acid $(\mathrm{HCl} 0.1 \mathrm{M}$ ) (metabolic trap, including the ${ }^{14} \mathrm{CO}_{2}$ resulting from catabolism) were prepared for scintillation counting by adding $12 \mathrm{~mL}$ or $10 \mathrm{~mL}$, respectively, of Ultima Gold XR (Rønnestad et al., 2001; Morais et al., 2005a). The samples were counted on a Beckman LS
6000IC (Beckman Instruments Inc, Fullerton, CA, USA) liquid scintillation counter and the results are presented as a percentage of dpm in each compartment, in relation to the total counts.

\subsection{Statistical analysis}

The data obtained for each treatment in terms of larval growth, total protein and lipid content, FA composition (only of total FA classes and of the quantitatively and qualitatively most important FA), enzymatic activity, as well as the distribution of label in each compartment after tube feeding, were compared through one-way and two-way (to examine the combined effect of the factors "lipid level" and "lipid source") analysis of variance (ANOVA), using the software Statistica 6 (StatSoft Inc., Tulsa, USA). The assumption of homogeneity of variance was checked using the Bartlett's test and a significance level of 0.05 was employed (Zar, 1996). Data from the tube feeding trial (percentage of counts found in each compartment) and all other percentage data were $\arcsin \left(x^{1 / 2}\right)$ transformed. When significant differences were found, the Tukey HSD multiple range test was performed. All data is given as mean values with standard deviations (S.D.).

\section{Results}

\subsection{Biochemical composition of the experimental diets}

The total protein content of the enriched Artemia varied between $28.7 \%$ and $34.9 \%$ while, for the total lipid content, the higher lipid diets (HS and HF) contained a higher lipid level than the corresponding low enrichment treatments (LS and LF), as expected, even if the difference was not too pronounced (particularly in the case of the fish oil diets) (Table 1).

In terms of FA composition, the differently enriched Artemia showed a different FA profile, reflecting the quantity and especially the composition of the oil used in the enrichment emulsion (Table 2). Thus, soybean oil-enriched Artemia (HS and LS), were characterized by a higher level of polyunsaturated FA (PUFA; FA $\geq 2$ double bonds) of the $n-6$ series, mainly linoleic acid $(18: 2 n-6)$, although the ARA content was lower than in Artemia enriched with fish oil. In terms of their n-3 HUFA content, particularly docosahexaenoic acid (22:6n-3; DHA) and EPA, zero and very low
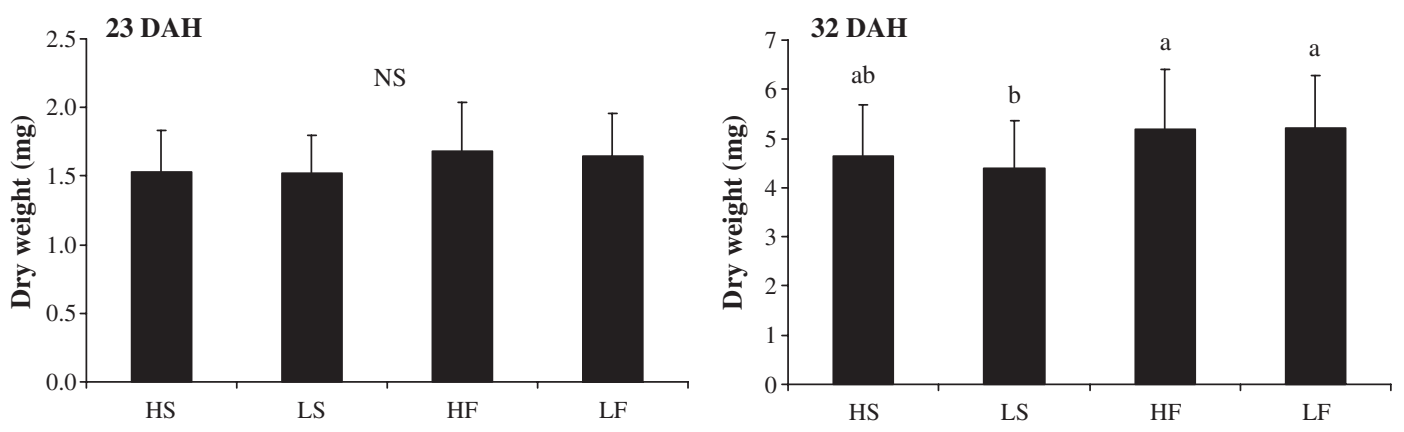

Fig. 1. Larval dry weight $(\mathrm{mg})$, at 23 and 32 DAH. Values are means $(n=60) \pm$ S.D. Columns with different letters are significantly different (one-way ANOVA, $P<0.05)$. NS - not significantly different. 
amounts, respectively, were found in both soybean oilenriched Artemia. Between the two soybean oil-enriched Artemia the main difference was the higher content of saturated FA (SFA), particularly palmitic (16:0) and stearic (18:0) acids, in LS Artemia which also showed the lowest content of total PUFA. Fish oil-enriched Artemia (HF and LF) were characterized by a higher level of ARA and n-3 PUFA, particularly of the HUFA DHA and EPA. These two later FA were present in lower amounts in LF Artemia, which had a higher linolenic acid (18:3n-3) content.

Table 3

Fatty acid composition (g/100g fatty acids) of the larvae at the start (14 DAH) and close to the end (32 DAH) of the experimental period

\begin{tabular}{|c|c|c|c|c|c|}
\hline & \multirow[t]{2}{*}{ Start (14 DAH) } & \multicolumn{4}{|c|}{ End of the experiment (32 DAH) } \\
\hline & & HS & $\mathrm{LS}$ & $\mathrm{HF}$ & LF \\
\hline $14: 0$ & $1.74 \pm 0.15$ & $0.61 \pm 0.00$ & $0.79 \pm 0.01$ & $1.32 \pm 0.05$ & $1.08 \pm 0.01$ \\
\hline $14: 1 n-5$ & $0.53 \pm 0.03$ & $0.39 \pm 0.01$ & $0.51 \pm 0.01$ & $0.41 \pm 0.02$ & $0.49 \pm 0.01$ \\
\hline $14: 1 n-7$ & $0.40 \pm 0.04$ & $0.16 \pm 0.01$ & $0.22 \pm 0.00$ & $0.27 \pm 0.01$ & $0.26 \pm 0.00$ \\
\hline $15: 0$ & $0.10 \pm 0.00$ & $0.08 \pm 0.00$ & $0.08 \pm 0.00$ & $0.06 \pm 0.03$ & $0.09 \pm 0.01$ \\
\hline $15: 1 n-5$ & $0.51 \pm 0.04$ & $0.44 \pm 0.00$ & $0.58 \pm 0.00$ & $0.41 \pm 0.02$ & $0.51 \pm 0.01$ \\
\hline 16:0iso & $0.18 \pm 0.13$ & $0.05 \pm 0.01$ & $0.09 \pm 0.01$ & $0.06 \pm 0.00$ & $0.07 \pm 0.00$ \\
\hline $16: 0$ & $17.76 \pm 1.44$ & $11.45 \pm 0.86$ & $13.52 \pm 0.09$ & $13.60 \pm 1.20$ & $14.20 \pm 0.78$ \\
\hline $16: 1 n-9$ & $1.00 \pm 0.31$ & $1.31 \pm 0.04$ & $1.28 \pm 0.03$ & $0.67 \pm 0.36$ & $0.57 \pm 0.01$ \\
\hline $16: 1 n-7$ & $3.19 \pm 0.10$ & $1.84 \pm 0.01$ & $2.18 \pm 0.03$ & $4.17 \pm 0.12$ & $3.20 \pm 0.13$ \\
\hline Me 16:0 & $0.13 \pm 0.01$ & $0.04 \pm 0.00$ & $0.05 \pm 0.00$ & $0.09 \pm 0.00$ & $0.07 \pm 0.00$ \\
\hline $16: 1 n-5$ & $0.67 \pm 0.05$ & $0.58 \pm 0.01$ & $0.85 \pm 0.00$ & $0.57 \pm 0.01$ & $0.68 \pm 0.00$ \\
\hline $16: 2 n-6$ & $0.97 \pm 0.06$ & $1.28 \pm 0.02$ & $1.26 \pm 0.00$ & $0.85 \pm 0.02$ & $1.01 \pm 0.02$ \\
\hline $17: 0$ & $0.43 \pm 0.02$ & $0.12 \pm 0.01$ & $0.17 \pm 0.01$ & $0.75 \pm 0.04$ & $0.52 \pm 0.08$ \\
\hline $16: 2 n-4$ & $0.66 \pm 0.05$ & $0.47 \pm 0.00$ & $0.70 \pm 0.02$ & $0.64 \pm 0.04$ & $0.70 \pm 0.02$ \\
\hline $16: 3 n-4$ & $0.59 \pm 0.04$ & $0.57 \pm 0.01$ & $0.72 \pm 0.00$ & $0.74 \pm 0.02$ & $0.68 \pm 0.06$ \\
\hline $16: 3 n-3$ & $0.19 \pm 0.09$ & $0.28 \pm 0.01$ & $0.20 \pm 0.01$ & $0.30 \pm 0.00$ & $0.27 \pm 0.06$ \\
\hline $16: 4 n-3$ & $0.49 \pm 0.02$ & $0.30 \pm 0.11$ & $0.36 \pm 0.15$ & $0.33 \pm 0.07$ & $0.33 \pm 0.05$ \\
\hline $16: 4 n-1$ & $0.27 \pm 0.02$ & $0.26 \pm 0.00$ & $0.30 \pm 0.05$ & $0.30 \pm 0.03$ & $0.24 \pm 0.01$ \\
\hline $18: 0$ & $8.35 \pm 0.58$ & $6.78 \pm 0.53$ & $8.64 \pm 0.14$ & $6.81 \pm 0.47$ & $7.89 \pm 0.55$ \\
\hline $18: 1 n-9$ & $20.14 \pm 0.72$ & $21.73 \pm 0.13$ & $21.00 \pm 0.04$ & $19.11 \pm 0.48$ & $19.03 \pm 0.44$ \\
\hline $18: 1 n-7$ & $6.55 \pm 0.24$ & $7.03 \pm 0.10$ & $8.64 \pm 0.07$ & $7.71 \pm 0.24$ & $8.20 \pm 0.27$ \\
\hline $18: 1 n-5$ & $0.15 \pm 0.01$ & $0.08 \pm 0.00$ & $0.04 \pm 0.06$ & $0.11 \pm 0.00$ & $0.11 \pm 0.00$ \\
\hline $18: 2 n-9$ & $0.27 \pm 0.01$ & $0.30 \pm 0.01$ & $0.38 \pm 0.00$ & $0.35 \pm 0.01$ & $0.39 \pm 0.01$ \\
\hline $18: 2 n-6$ & $10.11 \pm 0.44$ & $23.87 \pm 0.49^{\mathrm{a}}$ & $14.32 \pm 0.03^{\mathrm{b}}$ & $5.28 \pm 0.31^{\mathrm{c}}$ & $5.72 \pm 0.06^{\mathrm{c}}$ \\
\hline $18: 2 n-4$ & $0.00 \pm 0.00$ & $0.02 \pm 0.03$ & $0.02 \pm 0.03$ & $0.16 \pm 0.00$ & $0.06 \pm 0.08$ \\
\hline $18: 3 n-6$ & $0.32 \pm 0.01$ & $0.31 \pm 0.00$ & $0.39 \pm 0.00$ & $0.38 \pm 0.00$ & $0.40 \pm 0.00$ \\
\hline $18: 3 n-4$ & $0.00 \pm 0.00$ & $0.01 \pm 0.02$ & $0.02 \pm 0.03$ & $0.06 \pm 0.06$ & $0.03 \pm 0.05$ \\
\hline $18: 3 n-3$ & $10.25 \pm 1.17$ & $11.32 \pm 0.64^{\mathrm{a}}$ & $11.87 \pm 0.08^{\mathrm{ab}}$ & $12.80 \pm 0.20^{\mathrm{b}}$ & $14.49 \pm 0.57^{\mathrm{c}}$ \\
\hline $18: 4 n-3$ & $1.16 \pm 0.25$ & $0.79 \pm 0.07$ & $0.84 \pm 0.00$ & $1.38 \pm 0.03$ & $1.28 \pm 0.06$ \\
\hline $18: 4 n-1$ & $0.00 \pm 0.00$ & $0.00 \pm 0.00$ & $0.00 \pm 0.00$ & $0.04 \pm 0.03$ & $0.03 \pm 0.00$ \\
\hline $20: 0$ & $0.39 \pm 0.03$ & $0.28 \pm 0.02$ & $0.36 \pm 0.01$ & $0.23 \pm 0.02$ & $0.28 \pm 0.03$ \\
\hline $20: 1 n-9$ & $0.18 \pm 0.10$ & $0.75 \pm 0.00$ & $0.79 \pm 0.01$ & $1.16 \pm 0.03$ & $1.08 \pm 0.02$ \\
\hline $20: 1 n-7$ & $1.90 \pm 0.11$ & $0.27 \pm 0.02$ & $0.34 \pm 0.01$ & $0.29 \pm 0.01$ & $0.30 \pm 0.01$ \\
\hline $20: 2 n-9$ & $0.12 \pm 0.11$ & $0.03 \pm 0.00$ & $0.04 \pm 0.00$ & $0.04 \pm 0.06$ & $0.04 \pm 0.01$ \\
\hline $20: 2 n-6$ & $0.36 \pm 0.01$ & $0.81 \pm 0.02$ & $0.60 \pm 0.00$ & $0.30 \pm 0.01$ & $0.32 \pm 0.00$ \\
\hline $20: 3$ & $0.09 \pm 0.01$ & $0.12 \pm 0.00$ & $0.18 \pm 0.00$ & $0.16 \pm 0.01$ & $0.16 \pm 0.00$ \\
\hline $20: 4 n-6$ & $0.82 \pm 0.10$ & $0.60 \pm 0.31^{\mathrm{a}}$ & $1.32 \pm 0.04^{\mathrm{b}}$ & $1.60 \pm 0.04^{\mathrm{b}}$ & $1.56 \pm 0.03^{\mathrm{b}}$ \\
\hline $20: 3 n-3$ & $0.74 \pm 0.05$ & $1.13 \pm 0.01$ & $1.37 \pm 0.02$ & $0.87 \pm 0.06$ & $1.08 \pm 0.02$ \\
\hline $20: 4 n-3$ & $0.39 \pm 0.07$ & $0.33 \pm 0.02$ & $0.42 \pm 0.01$ & $0.63 \pm 0.02$ & $0.59 \pm 0.00$ \\
\hline $20: 5 n-3$ & $1.98 \pm 0.45$ & $0.67 \pm 0.06^{\mathrm{a}}$ & $1.06 \pm 0.01^{\mathrm{a}}$ & $4.22 \pm 0.09^{\mathrm{b}}$ & $3.25 \pm 0.01^{\mathrm{c}}$ \\
\hline $22: 1 n-11$ & $1.30 \pm 0.09$ & $0.00 \pm 0.00$ & $0.05 \pm 0.07$ & $0.65 \pm 0.07$ & $0.68 \pm 0.00$ \\
\hline $22: 1 n-9$ & $0.22 \pm 0.04$ & $0.10 \pm 0.00$ & $0.09 \pm 0.00$ & $0.16 \pm 0.01$ & $0.16 \pm 0.00$ \\
\hline $22: 4 n-6$ & $0.08 \pm 0.01$ & $0.03 \pm 0.04$ & $0.04 \pm 0.06$ & $0.16 \pm 0.00$ & $0.14 \pm 0.00$ \\
\hline $22: 5 n-6$ & $0.00 \pm 0.00$ & $0.03 \pm 0.05$ & $0.06 \pm 0.03$ & $0.06 \pm 0.05$ & $0.08 \pm 0.00$ \\
\hline $22: 5 n-3$ & $1.29 \pm 0.33$ & $0.62 \pm 0.00$ & $0.90 \pm 0.01$ & $3.09 \pm 0.21$ & $2.23 \pm 0.07$ \\
\hline $22: 6 n-3$ & $2.98 \pm 0.45$ & $1.72 \pm 0.06^{\mathrm{a}}$ & $2.37 \pm 0.05^{\mathrm{a}}$ & $6.69 \pm 0.20^{\mathrm{b}}$ & $5.43 \pm 0.18^{\mathrm{c}}$ \\
\hline \multicolumn{6}{|l|}{ Totals } \\
\hline SFA & $29.08 \pm 2.27$ & $19.42 \pm 1.40^{\mathrm{a}}$ & $23.70 \pm 0.22^{\mathrm{ab}}$ & $22.91 \pm 1.67^{\mathrm{ab}}$ & $24.21 \pm 1.28^{\mathrm{b}}$ \\
\hline MUFA & $36.75 \pm 1.07$ & $34.67 \pm 0.17^{\mathrm{a}}$ & $36.56 \pm 0.17^{\mathrm{a}}$ & $35.69 \pm 0.96^{\mathrm{a}}$ & $35.27 \pm 0.90^{\mathrm{a}}$ \\
\hline PUFA & $34.14 \pm 3.19$ & $45.88 \pm 1.29$ & $39.74 \pm 0.06$ & $41.40 \pm 1.21$ & $40.52 \pm 0.38$ \\
\hline HUFA & $7.53 \pm 1.38$ & $4.01 \pm 0.23^{\mathrm{a}}$ & $6.18 \pm 0.00^{\mathrm{b}}$ & $16.44 \pm 0.48^{\mathrm{c}}$ & $13.29 \pm 0.05^{\mathrm{d}}$ \\
\hline n-3 PUFA & $19.49 \pm 2.81$ & $17.15 \pm 0.63^{\mathrm{a}}$ & $19.39 \pm 0.08^{\mathrm{b}}$ & $30.31 \pm 0.74^{\mathrm{c}}$ & $28.94 \pm 0.44^{\mathrm{c}}$ \\
\hline n-6 PUFA & $12.65 \pm 0.47$ & $26.94 \pm 0.71^{\mathrm{a}}$ & $18.00 \pm 0.03^{\mathrm{b}}$ & $8.62 \pm 0.41^{\mathrm{c}}$ & $9.24 \pm 0.13^{\mathrm{c}}$ \\
\hline$n-3 / n-6$ & $1.54 \pm 0.19$ & $0.64 \pm 0.01$ & $1.08 \pm 0.01$ & $3.52 \pm 0.09$ & $3.13 \pm 0.00$ \\
\hline
\end{tabular}

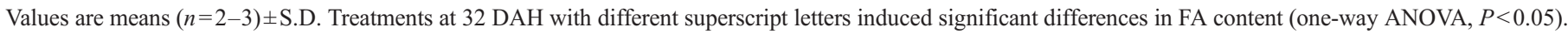



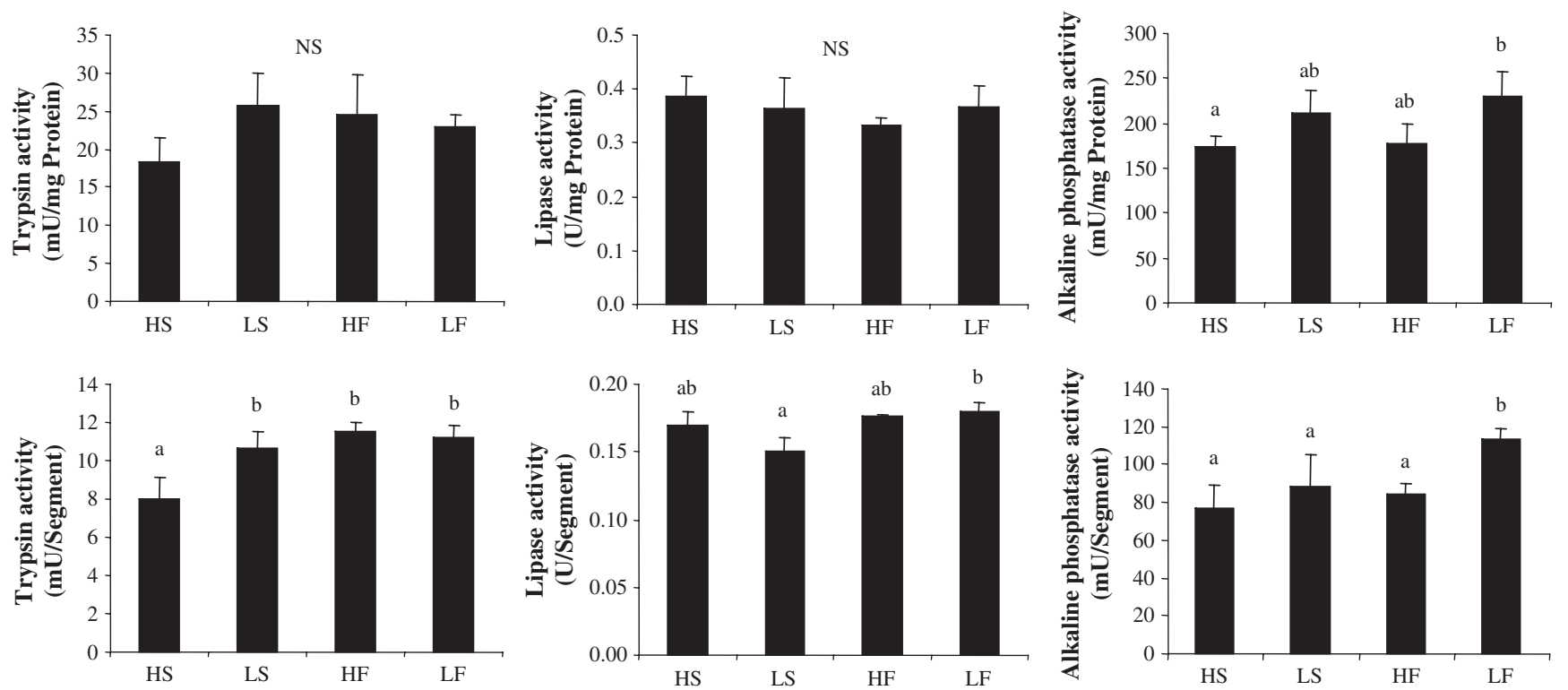

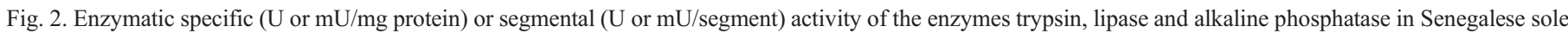

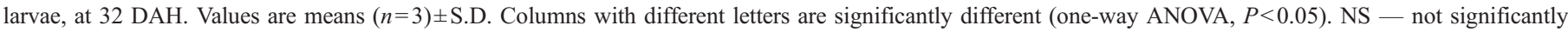
different.

\subsection{Larval growth and biochemical composition}

At 23 DAH no statistically significant differences in growth were noted between larvae fed the different experimental regimes $(P>0.05$; one-way ANOVA), while at $32 \mathrm{DAH}$ the soybean oil treatments appeared to induce a lower growth than the fish oil diets, although only significantly for LS (Fig. 1). When a two-way ANOVA was performed, the factor "lipid level" was not found to significantly affect larval growth, while "lipid source" had a significant effect both at 23 DHA $(P<0.05)$ and at $32 \mathrm{DAH}(P<0.001)$.

In terms of total protein and lipid content (Table 1), no significant differences were noted between the larvae fed different experimental regimes, although larvae fed on HF Artemia tended to have slightly higher total lipid content and a correspondingly lower total protein composition, while the inverse appeared to occur for larvae fed the LF Artemia. Analyzing the results through a two-way ANOVA revealed a significant effect of "lipid level" on the larval protein content, with larvae fed the low lipid treatments showing a higher protein level, but no significant differences were found in total lipid content.

The FA composition of the larvae and the changes noted from 14 to 32 DAH generally reflected the dietary FA profile (Table 3). Larvae of 32 DAH showed a reduction in SFA, particularly in those fed HS Artemia, in comparison with those at the beginning of the experiment (14 DAH). Larvae fed soybean oil-enriched Artemia (HS and LS) had a significantly lower content of EPA, DHA and n-3 HUFA and a higher level of n-6 PUFA. Larvae fed HS Artemia presented the significantly highest total n-6 PUFA content, particularly of linoleic acid, and the significantly lowest ARA level, together with significantly lower contents of n-3 PUFA and HUFA than LS Artemia. On the other hand, larvae fed fish oil-enriched Artemia presented significantly lower n-6 and higher n-3 PUFA contents, as well as higher HUFA levels (mainly EPA and DHA), which were significantly highest in HF larvae. The two-way ANOVA has shown a significant effect of both "lipid level" and "lipid source" on all the analyzed FA and total FA classes, except for SFA (only "lipid level" was significant), HUFA and n-3 PUFA (only "lipid source" was significant). However, in all cases there was also a significant interaction between factors.

\subsection{Larval enzymatic activity}

At $34 \mathrm{DAH}$ there were no significant differences in trypsin specific activity in terms of protein content, but HS-fed larvae showed a significantly lower trypsin segmental activity (Fig. 2). Similarly, for lipase no significant differences were found in terms of specific activity. However, the LS treatment was responsible for a significantly lower lipase segmental activity than the LF treatment. The activity of alkaline phosphatase, an enzyme involved in nutrient absorption, was also assayed. In this case, the LF treatment was responsible for a higher specific activity (although only significantly different from HS) and segmental activity. When a two-way ANOVA was performed to analyze enzymatic specific activity, significant differences were only found for alkaline phosphatase for the factor "lipid level", being the low lipid Artemia responsible for a significantly higher alkaline phosphatase specific activity in larvae fed these diets. In

\section{Table 4}

Evaluation of the histological appearance (accumulation of lipid droplets) in the gut and liver of 32 DAH Senegalese sole larvae fed different experimental diets $(n=10) .0=$ not observed; $1=$ scarce; $2=$ moderate; $3=$ numerous

\begin{tabular}{llll}
\hline Diet & Gut & Liver \\
\cline { 2 - 3 } & Anterior intestine & Posterior intestine & \\
\hline HS & 1 & 3 & 3 \\
LS & 1 & 1 & 2 \\
HF & 1 & 3 & 3 \\
LF & 1 & 2 & 2 \\
\hline
\end{tabular}



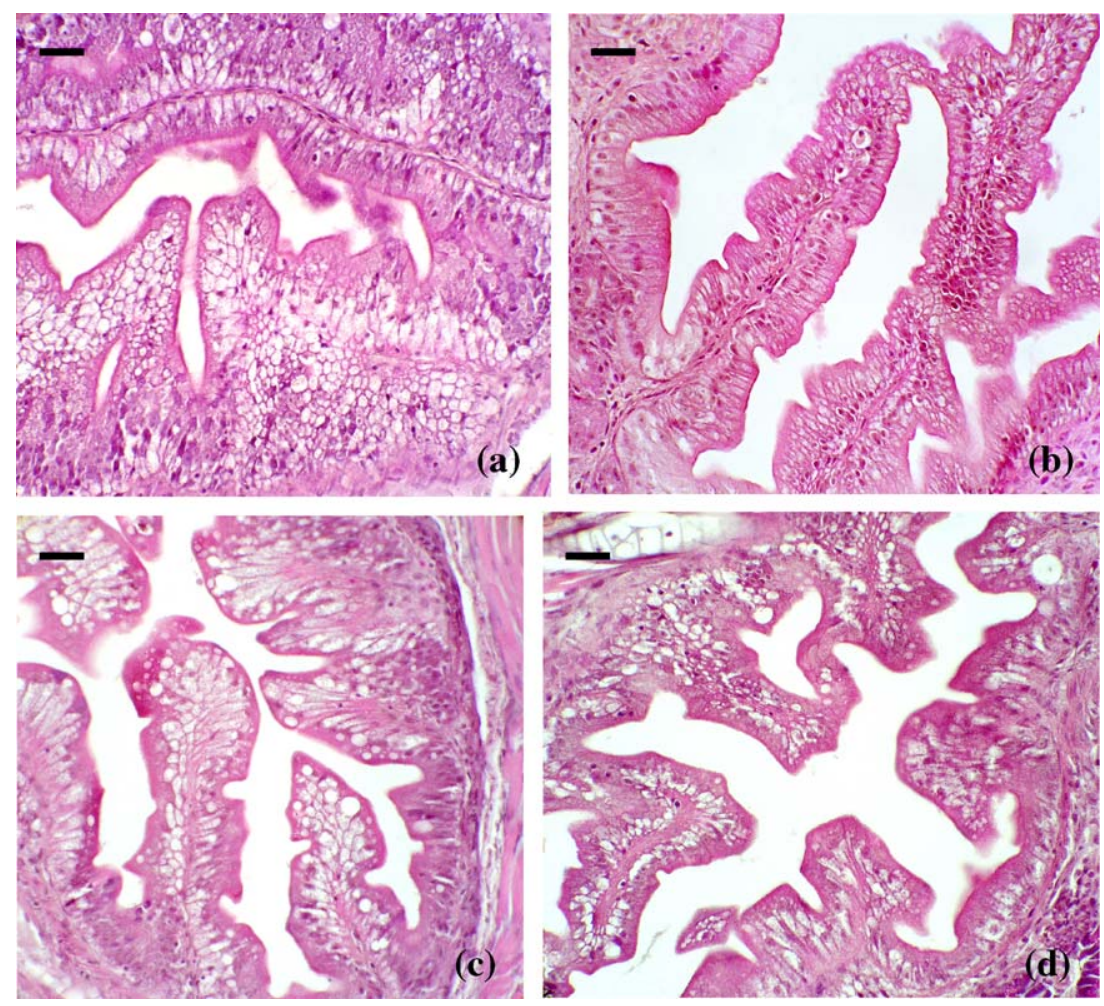

Fig. 3. Histological appearance of the anterior intestine of $32 \mathrm{DAH}$ Senegalese sole larvae $(\mathrm{H} \& \mathrm{E}, \times 400)$. Large lipid accumulations were detected in the basal zone of the enterocytes in larvae fed HS (a) and HF (c) Artemia, while scarce lipid accumulation was observed in the enterocytes of larvae on the LS treatment (b), and intermediate on the LF treatment (d). Bar $=25 \mu \mathrm{m}$.
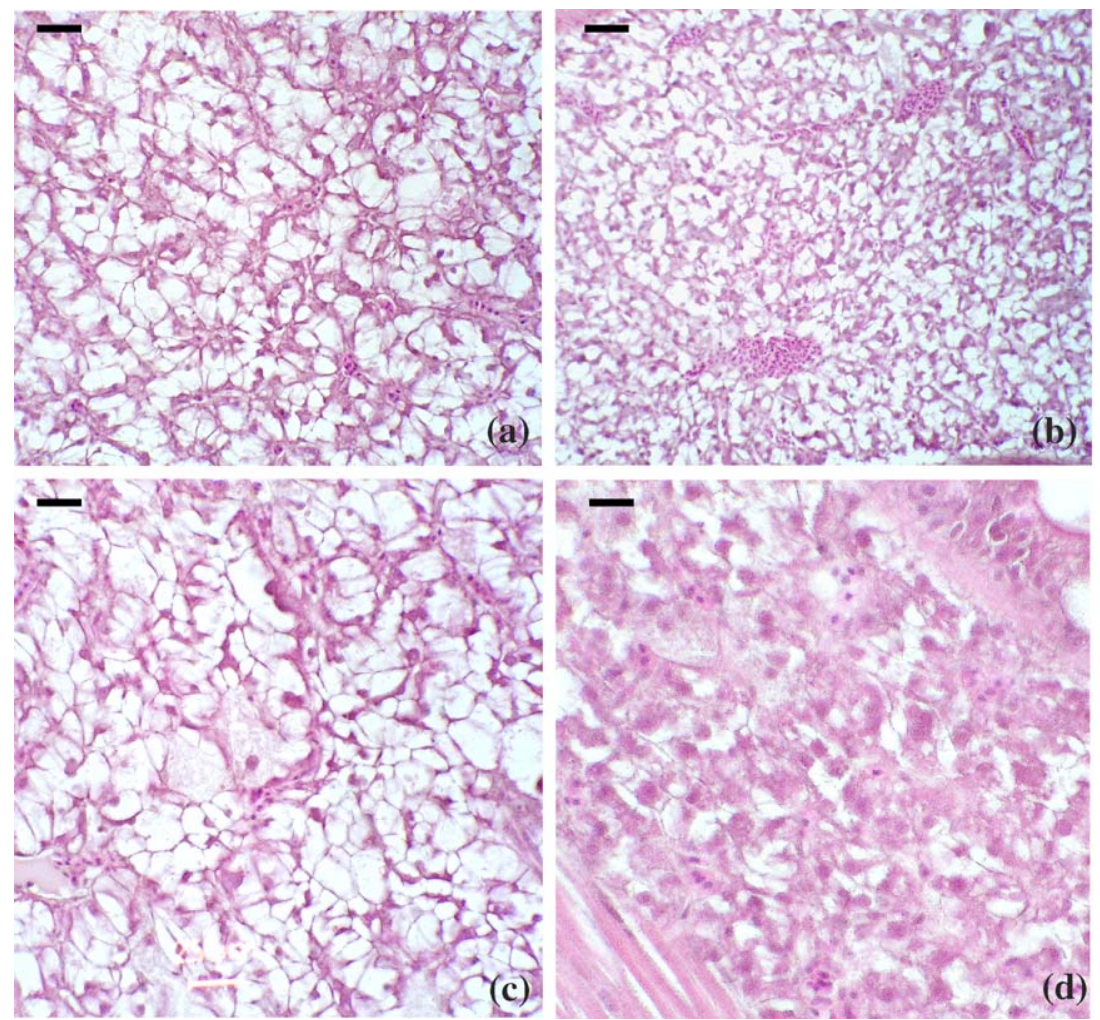

Fig. 4. Histological appearance of the liver of $32 \mathrm{DAH}$ Senegalese sole larvae $(\mathrm{H} \& \mathrm{E}, \times 400)$. An intense accumulation of lipid vacuoles was observed in the hepatocytes of larvae fed HS (a) and HF (c) Artemia and less so in larvae fed the LS (b) and LF (d) treatments. Bar $=25 \mu \mathrm{m}$. 
terms of segmental activity, significant differences were found in all assayed enzymes for the factor "lipid source", with the soybean oil-enriched Artemia inducing lower enzymatic activities. The factor "lipid level" was significantly different for trypsin segmental activity (but in this case there was also a significant interaction between factors) and for alkaline phosphatase segmental activity (same differences as with specific activity).

\subsection{Histological analysis}

The examination of the histological sections showed that, in general, lipid accumulation in the enterocyte was higher in the posterior intestine than in the anterior intestine. In the anterior intestine, a scarce accumulation of lipid was observed in all diets while in the posterior intestine very large lipid accumulations were detected in the basal zone of the enterocytes (Table 4 and Fig. 3). This was particularly noticeable in larvae fed Artemia enriched with higher lipid doses (HS and HF). The LS diet induced the lowest lipid accumulation in the posterior intestine enterocytes. With respect to the liver, larvae fed diets containing the highest lipid levels showed an intense accumulation of lipid vacuoles in the hepatocytes, being this moderate for larvae fed the LS and LF diets (Table 4 and Fig. 4).

\subsection{Tube feeding trial}

When the larvae submitted to the different dietary regimes were tube fed either TRI or OA (the free FA that composes the triacylglycerol TRI), considerable differences were seen in the absorption and metabolism of these labels (Fig. 5). Firstly, TRI was much more evacuated by the larvae, independently of their feeding regime. Therefore, TRI was little retained in the gut and body tissues, compared to OA. In addition, the absorbed TRI was mostly catabolised. If the amount of catabolised label is expressed in terms of percentage of total absorbed label, a catabolism of $88 \%, 41 \%, 75 \%$ and $72 \%$ of total absorbed TRI was measured for the HS, LS, HF and LF treatments, respectively, while the catabolism was significantly lower for the tube fed OA $-17 \%, 23 \%, 19 \%$ and $19 \%$ for larvae fed HS, LS, HF and LF, respectively.

Tube feeding TRI resulted in significant differences between larvae submitted to different experimental treatments, in the amount of label that was found in the analyzed compartments. Larvae fed the LS treatment showed a significantly lower TRI evacuation than larvae fed the HS Artemia, while larvae fed fish oil-enriched Artemia (HF and LF) showed an intermediate and non-significantly different evacuation. Consequently, larvae fed the LS Artemia presented a higher absorption of TRI and the significantly highest label retention in the gut and body tissues. No significant differences were measured between treatments in the metabolic trap compartment but when the catabolism results were expressed in terms of percentage of total label absorbed, the LS treatment showed a significantly lower TRI catabolism, compared to the remaining treatments, which were not significantly different from each other. The LS treatment induced
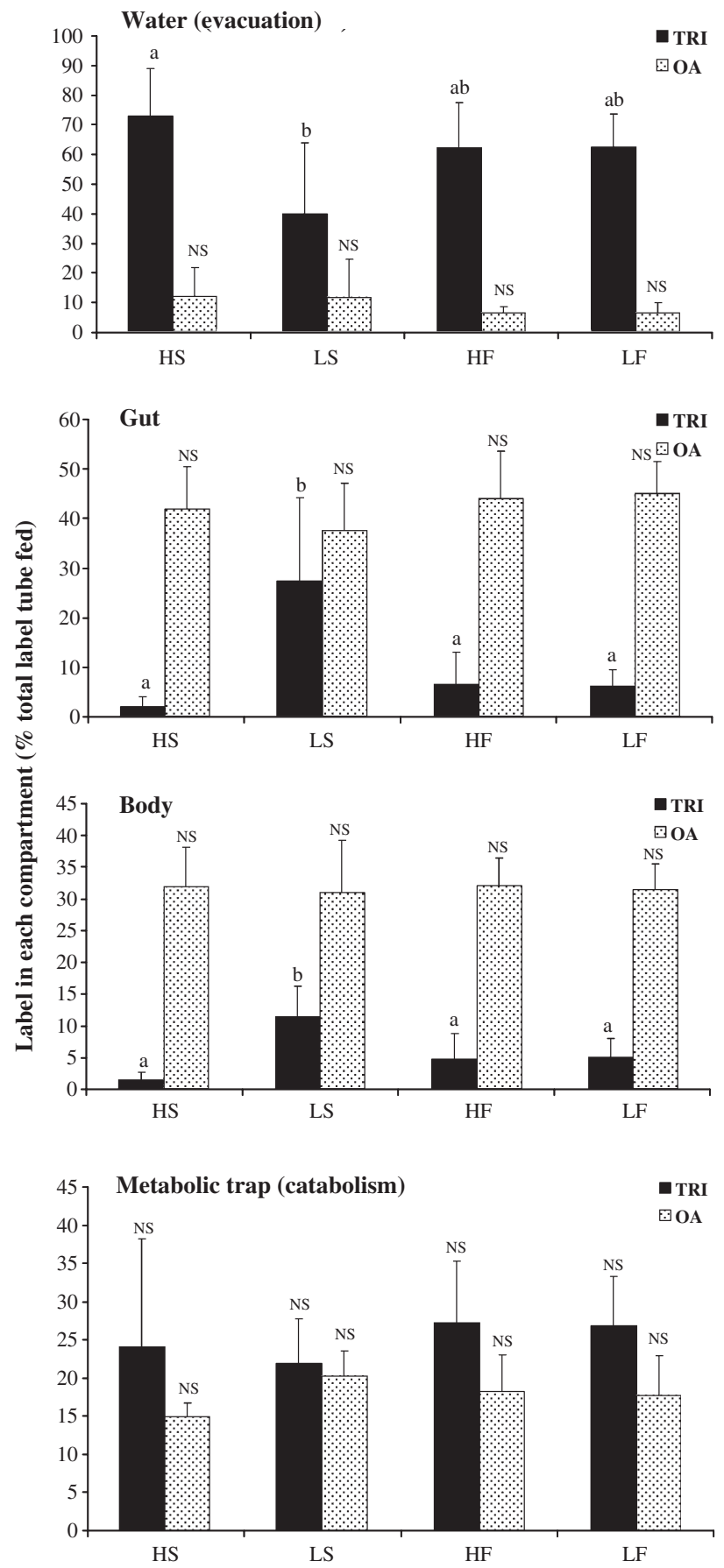

Fig. 5. Label found in each compartment ( $\%$ of total label tube fed), $24 \mathrm{~h}$ after tube feeding $S$. senegalensis larvae that were previously fed different experimental diets (HS, LS, HF or LF) with either ${ }^{14} \mathrm{C}$-TRI (triolein) or ${ }^{14} \mathrm{C}-\mathrm{OA}$ (oleic acid). Values are means $(n=6) \pm$ S.D. Different letters in different dietary treatments which were tube fed the same radiolabel indicate significant differences (one-way ANOVA, $P<0.05$ ). NS - not significantly different.

such large differences that in most compartments (except in the metabolic trap) the two-way ANOVA detected a significant effect of the factor "lipid level" (and also of "lipid source" in the gut compartment), but always accompanied by a significant interaction between both factors. On the other hand, when OA was tube fed, no significant differences were found (both through one-way and two-way ANOVA) in the way the larvae 
submitted to different dietary treatments absorbed and metabolized this label.

\section{Discussion}

Enriching Artemia with different doses of lipid emulsion did not enable achieving large differences in total lipid level between the high and low lipid Artemia. The effect of total neutral lipid level on Senegalese sole larval growth and nutrient absorption efficiency has been addressed before but using non-enriched Artemia as the lower lipid diet (Morais et al., 2005a,b). However, even if larger differences in total lipid level were achieved in such way, the experimental treatments most probably differed on their relative FA profile and it can be argued that the observed effects might be linked to the FA composition of the diet and are not only due to dietary lipid level. The present and previous studies have evidenced the problems faced with approaches using live feed to study the relative importance of dietary lipid levels and FA compositions in growth performance, digestive physiology and lipid metabolism, as it is very difficult to accurately manipulate both simultaneously in a living organism. The need for effective formulated diets, allowing better control of the dietary composition and limiting the effect of factors acting simultaneously, is clear and vital, in order to advance in this field. Fortunately, considerable progress has been achieved in the development of inert diets in the last few years (Koven et al., 2001; Cahu et al., 2003; Langdon, 2003; Yúfera et al., 2003) and some prototype diets are now becoming available for experimental work.

In the present study, feeding Senegalese sole on Artemia enriched with a high or low dose of lipid emulsion did not affect significantly larval growth and the type of lipid source appeared to have a more important effect. Thus, fish oil-enriched Artemia induced a better growth than the soybean oil-enriched one, in agreement with the higher n-3 HUFA content of the former. However, growth reduction was slightly and non-significantly more pronounced in larvae fed soybean oil-enriched Artemia at lower lipid levels, possibly denoting a situation of marginal EFA, energy and/or protein deficiencies. Accordingly, larval FA profile closely reflected the quantitative and qualitative FA composition of their diet, as is commonly found in fish larvae and has been described before for Senegalese sole larvae (Morais et al., 2004b).

Slight dietary effects could be noted in the activity of enzymes involved in the digestive and absorptive processes, mostly in terms of segmental activity. However, the results indicate a relationship between larval size and the enzymatic activity in the dissected digestive tracts, as the two-way ANOVA revealed significant differences in segmental activity for all assayed enzymes for the factor "lipid source". The soybean oilenriched Artemia treatments, which induced a lower larval growth and a lower digestive tract weight (data not shown), were also responsible for lower enzymatic activities. Nonetheless, the soybean oil in higher doses may have had a particularly depressing effect on trypsin activity, as a significantly lower segmental activity (and a non-significant trend in specific activity; one-way ANOVA) was measured in larvae fed the HS diet, whose size was not significantly different from the remaining treatments. At 34 DAH the LS treatment was responsible for a significantly lower lipase segmental activity than the LF Artemia (one-way ANOVA). In a previous study performed with seabass larvae, the dietary lipid level was not found to affect lipase activity but the source of dietary lipid had a significant affect (Morais et al., 2004a). The differential lipase response was explained as being possibly caused by differences in the FA composition of the diet, related to the specificity of lipase towards FA differing in chain length and degree of saturation. The method utilized in the present experiment is most likely determining the activity of the non-specific bile saltactivated lipase which has been shown to have a higher affinity for PUFA (Iijima et al., 1998; Izquierdo et al., 2000). Nevertheless, as mentioned above, the smaller size of LS larvae must be at least partly responsible for the reduction in segmental lipase activity. In terms of specific activity (i.e., after standardizing for larval size using protein content), no significant differences were found, even if there was a trend for a lower specific activity in larvae fed the HF Artemia. A reduction in lipase specific activity caused by formulated diets containing fish oil has been noted in 52 DAH seabass by Morais et al. (2004a), where it was suggested that the higher digestibility of the diets containing PUFA and HUFA could eventually cause an adaptative response leading to lower lipase secretion. Regarding the alkaline phosphatase activity, a trend for higher activity was noted when larvae were fed lower lipid diets (particularly LF), and this "lipid level" effect was significant when a two-way ANOVA was performed, both in terms of segmental and specific activity. The alkaline phosphatase is involved in nutrient absorption and transport across the intestinal epithelia and its activity has been related to food intake (Fraisse et al., 1981). Ribeiro et al. (1999) has found a trend for higher alkaline phosphatase activity in Senegalese sole that were seen to feed more actively. In a previous study conducted with Senegalese sole larvae it was shown that feeding the larvae with Artemia enriched on a soybean oil emulsion, when compared to non-enriched Artemia, appeared to result in a slower amino acid absorption and it was suggested that this may result in a slower clearance of the gut lumen with potential effects in the reduction of food intake (Morais et al., 2005b). Nevertheless, in the present study the food intake was not measured and even if the possibility exists that a higher dietary lipid level might potentially lead to a lower food intake in sole larvae, this can only be speculated at the moment and further studies are necessary.

Increased lipid content in Artemia markedly increased the amount of lipid droplets found in the posterior intestine epithelia, denoting the higher lipid absorption in these larvae. On the contrary, the lowest enterocyte lipid accumulation found in larvae fed Artemia enriched with a low dose of soybean oil is in agreement with the lowest lipid level found in this dietary treatment. It has been suggested that the dietary FA composition may alter the intestinal membrane composition, leading to changes in its morphological structure and fluidity, and may affect intestinal lipid metabolism and transport (Caballero et al., 2002 , 2003). One of the suggested potential metabolic effects would be in the intracellular pathways of triacylglycerol (TAG) 
and phospholipid (PL) reacylation, which appear to be affected by the nature of dietary lipids (Sire and Vernier, 1981; Izquierdo et al., 2000; Olsen et al., 2000b). In this respect, van Greevenbroek et al. (1995), working with Caco-2 cells derived from a human colorectal carcinoma, noted that the intracellular lipid resynthesis differed according to the nature of the FA, with palmitic acid (16:0) increasing PL synthesis, while the presence of linoleic acid (18:2n-6) in the culture media led to higher amounts of TAG being synthesized. In fish, relatively little is known regarding the pathways of lipid reesterification within the enterocytes and how these may be affected by dietary FA nature. Olsen et al. (2000b) found that replacing a part of dietary linseed oil by 16:0 reduced significantly lipid droplet accumulation in the enterocytes. In addition, Caballero et al. (2004) found that in seabream the intestinal TAG and PL biosynthesis is affected by the type and FA composition of the vegetable oil included in the diet, with soybean oil diets resulting in a high production of phosphatidylcholine. Moreover, Pérez et al. (1999) noted that different radiolabelled FA incubated in vitro with trout enterocytes showed a different post-absorptive reesterification fate, particularly concerning PL synthesis. Nevertheless, in Oxley et al. (2005), the replacement of fish oil by vegetable oil in the diet of Atlantic salmon did not affect significantly the lipid class composition of the gut mucosa or the activity of the enzymes involved in the intestinal reacylation of digested lipid into TAG or PL. In the present study, the differences in lipid accumulation within the enterocytes appeared to be directly correlated to the dietary quantitative supply of neutral lipid and no dietary influence in terms of FA composition was noted.

The lipid vacuoles were localized mostly in the basal zone of the enterocyte in all treatments, implying a reacylation of the dietary FA. In addition, no lipid accumulation was observed in the enterocyte intercellular spaces, indicating that there were no problems of lipid transport into the body circulation. Salhi et al. (1999), when feeding larval seabream (Sparus aurata) with high dietary neutral lipid content, also observed increased lipid vacuoles in the basal zone of the enterocytes, suggesting a reduction in the lipid transport rate from the intestinal mucosa to the blood. In rats, it was noted that the rate of FA esterification may regulate FA absorption from the lumen (Borgström, 1977) and, in adult fish, lipid accumulation within the enterocytes has been reported and is believed to result from a slower lipid processing, compared to mammals, where there is a temporal separation between FA absorption and secretion by the intestinal tissue (Noaillac-Depeyre and Gas, 1974; Sire and Vernier, 1981). In ectothermic fish there are differences between the rate of luminal lipid digestion and diffusion of FA into the gut epithelia, which are not affected by water temperature, and the rate of reacylation into TAG and lipoprotein synthesis, which are slowed down by low water temperatures (Sire and Vernier, 1981). The results from the present study give support to this idea and the intracellular location of the lipid droplets denote a problem at the level of lipoprotein synthesis and/or secretion rather than in FA reacylation.

Similarly to what was observed in the enterocytes of sole larvae, the accumulation of lipid droplets in the hepatocytes was higher in the higher lipid diets (HS and HF), independently of their lipid source, suggesting an important effect of dietary total lipid level.

The histology results also showed that the posterior intestine section of the digestive tube of sole was more active in absorbing dietary lipid than the anterior intestine. The capacity for lipid absorption by the intestinal epithelium has been noted from the onset of exogenous feeding in many fish species, although the specific localization of the predominant absorption site in the digestive tract segment varies with species (Izquierdo et al., 2000). In carp, rainbow trout, cod and Arctic char, lipid absorption was demonstrated to occur mainly in the proximal region of the intestine and in the pyloric caeca (Noaillac-Depeyre and Gas, 1974; Sire et al., 1981; Lie et al., 1987; Olsen et al., 1999), whereas in turbot the posterior area of the gastrointestinal tract, mainly the posterior intestine and rectum regions, was described as being more active (Koven et al., 1994).

When sole larvae that had been fed on different experimental diets were tube fed ${ }^{14} \mathrm{C}$-labeled TRI, the LS treatment induced a significantly lower label evacuation than the HS diet, together with a significantly higher absorption into the gut and body tissues. However, no significant differences in TRI absorption were noted between larvae fed HF or LF Artemia. The total dietary lipid level might explain these results, as the difference between the total lipid of the Artemia enriched with higher or lower doses of fish oil (HF and LF) was lower than that obtained when enriching the Artemia with a soybean oil emulsion (HS and LS). This difference in total lipid level of the diets was probably of physiological significance, as the histological appearance of the larval gut mucosa appears to confirm. Therefore, these results substantiate previous suggestions that a high dietary neutral lipid supply may result in an overload of the enterocyte with lipid droplets, which in turn may decrease FA absorption efficiency (Morais et al., 2005a).

In addition, the tube feeding results show that, independently of the feeding regime and in comparison to OA, TRI was much more evacuated into the incubation water and was little retained in the gut and body, corroborating previous results that sole larvae have a lower capacity to absorb a TAG, which still needs to be digested, compared to a free FA (Morais et al., 2005a). Nonetheless, these results are not in agreement with previous observations by Izquierdo et al. $(2000,2001)$ in larvae of seabream, where OA was better incorporated into the body lipids when it was provided in a microdiet esterified to TAG rather than as free FA. The authors suggested a limited capacity of reacylation or transport of free FA, or its preferential utilization as energy source in the enterocyte, as possible explanations. This discrepancy between both studies could be related to differences in the activity of the enzymes involved in lipid digestion in each fish species, since a lower total bile salt-activated lipase activity has been found in another flat fish, Psetta maxima, in comparison with several sparids, including gilthead seabream (Izquierdo et al., 2000). More studies on the digestive processes of both species are necessary to determine if this difference is species-specific or related to methodological differences, such as the type of feed used in these studies.

On the other hand, in contrast to what was observed with TRI, when OA was tube fed no significant differences were found in 
the way the larvae absorbed and metabolized this label, which might indicate that the factors which were affecting the absorption of the triacylglycerol label (TRI) did not affect the absorption of a free FA. Differences in lipase activity and thus in the ability of larvae submitted to different dietary regimes to digest TRI cannot explain these results which must then be related to absorption aspects. The reason why the lipid droplet accumulation within the basal region of the enterocytes had an influence on TRI absorption but did not affect OA cannot be explained and contradict the previous study where this accumulation affected both TRI and OA absorption (Morais et al., 2005a). Differences in the dietary quantitative supply of neutral lipid and in the subsequent accumulation of lipid in the enterocytes might partly explain the differences between the present and the latter study.

The tube feeding trial also showed that a considerably higher proportion of OA is used for the production of energy (i.e., catabolised) when supplied as TRI rather than in the free form. This has been noted previously in Senegalese sole larvae (Morais et al., 2005a) and it was suggested that the metabolic fate of $\mathrm{OA}$ depends on its dietary molecular form, being significantly more catabolised when supplied esterified to a TAG (TRI), the usual provider of FA for beta-oxidation, than when esterified to a PL (L-3-phosphatidylcholine-1,2-dioleoyl) or in the free form. It seems, however, puzzling that $\mathrm{OA}$ in its free form is absorbed and subsequently metabolized differently from when it is tube fed esterified to TRI which, in adult fish, is at least partly digested to $\mathrm{OA}$ and 2monoacylglycerol or even entirely to OA and glycerol before absorption (Sire et al., 1981; Koven et al., 1994), although the digestive process is not completely known in larvae and differences may exist. Nevertheless, these results may be explained simply by differences in total absorption of OA when supplied bound to TRI or in the free form. If OA is highly utilized for energetic purposes by fish larvae, as has been postulated by Rodríguez et al. (1994) and Izquierdo et al. (2001), it could be possible that when it is absorbed in very large amounts, as appears to be the case of OA, a more substantial fraction would be directed into anabolic pathways, enhancing its accumulation in the gut and other body tissues. Thus, when larvae were fed LS Artemia, a significantly higher amount of label was absorbed, meaning that a larger proportion of FA will remain after catabolism, explaining the higher label retention in the gut and body tissues of these larvae. On the contrary, in the HS treatment, a significantly lower amount of TRI was absorbed compared to larvae fed LS Artemia, resulting in a much higher proportion of label being catabolised (and thus less retained) when expressed as a percentage of total label absorbed.

The results described in the present paper confirm earlier suggestions linking an increase in total neutral lipid content of the diet with the accumulation of lipid droplets within the basal zone of the gut enterocytes and a decrease in the absorption of labeled FA, i.e., in the rate of lipid export from the enterocyte into the body circulation. However, the differences between the total lipid content of the high and low enriched Artemia did not allow finding an effect on larval growth, which was only affected by the type of lipids. Thus, the enrichment of Artemia with fish oil, rich in HUFA, slightly enhanced growth, both at high and low doses. In this case, the enhanced growth of larvae fed these Artemia is likely due to the higher dietary supply of EFA, for which there are specific mechanisms of absorption and reacylation into structural lipids, independently of the presence of lipid droplet accumulation in the enterocytes. Finally, OA appeared to be preferentially utilized for energy production, accumulating more in larval tissues when absorbed in higher amounts (e.g., when supplied as OA in its free form or as TRI in larvae fed LS-Artemia).

\section{Acknowledgements}

Sofia Morais was supported by a $\mathrm{PhD}$ scholarship from "Fundação para a Ciência e a Tecnologia", Portugal (SFRH/ BD/4902/2001). This work benefited from funding by Project DIVERAQUA/SP5.E36 (programme INTERREG III A, Cofunded by FEDER, European Commission). The authors would like to acknowledge IPIMAR-CRIPSul (Olhão, Portugal) for the supply of Senegalese sole larvae and Laura Ribeiro for providing some of the enzymatic analysis protocols.

\section{References}

Bessey, O.A., Lowry, O.H., Brock, M.J., 1946. A method for the rapid determination of alkaline phosphatase with five cubic millimeters of serum. J. Biol. Chem. 164, 321-329.

Borgström, B., 1977. Digestion and absorption of lipids. In: Crane, R.K. (Ed.), International Review of Physiology. Gastrointestinal Physiology II, vol. 12. University Park Press, Baltimore, USA, pp. 305-323.

Bradford, M.M., 1976. A rapid and sensitive method for the quantitation of microgram quantities of protein utilizing the principle of protein-dye binding. Anal. Biochem. 72, 248-254.

Caballero, M.J., Obach, A., Rosenlund, G., Montero, D., Gisvold, M., Izquierdo, M.S., 2002. Impact of different dietary lipid sources on growth, lipid digestibility, tissue fatty acid composition and histology of rainbow trout, Oncorhynchus mykiss. Aquaculture 214, 253-271.

Caballero, M.J., Izquierdo, M.S., Kjørsvik, E., Montero, D., Socorro, J., Fernández, A.J., Rosenlund, G., 2003. Morphological aspects of intestinal cells from gilthead seabream (Sparus aurata) fed diets containing different lipid sources. Aquaculture 225, 325-340.

Caballero, M.J., Izquierdo, M.S., Montero, D., Robaina, L., Fernández, A., 2004. Is the intestinal biosynthesis of triacylglycerol and phospholipids affected by the inclusion of vegetable oils in diets for sea bream (Sparus aurata)? Proceedings of the 11th International Symposium on Nutrition and Feeding in Fish, p. 201.

Cahu, C.L., Zambonino Infante, J.L., Barbosa, V., 2003. Effect of dietary phospholipid level and phospholipid: neutral lipid value on the development of sea bass (Dicentrarchus labrax) larvae fed a compound diet. Br. J. Nutr. 90, $1-9$.

Diaz, J.P., Guyot, E., Vigier, S., Connes, R., 1997. First events in lipid absorption during post-embryonic development of the anterior intestine in gilt-head sea bream. J. Fish Biol. 51, 180-192.

Dinis, M.T., Ribeiro, L., Soares, F., Sarasquete, C., 1999. A review on the cultivation potential of Solea senegalensis in Spain and in Portugal. Aquaculture 176, 27-38.

Folch, J., Lees, M., Sloane-Stanley, G.H., 1957. A simple method for the isolation and purification of total lipids from animal tissues. J. Biol. Chem. 226, 497-509. 
Fox, C., 1990. Studies on polyunsaturated fatty acid nutrition in larvae of marine fish-the herring, Clupea harengus L. PhD Thesis. University of Stirling, UK, 196 pp.

Fraisse, M., Woo, N.Y.S., Noaillac-Depeyre, J., Murat, J.C., 1981. Distribution patterns of digestive enzyme activities in the intestine of the catfish (Ameiurus nebulosus L.) and of the carp (Cyprinus carpio L.). Comp. Biochem. Physiol., A 70, 443-446.

Han, K., Geurden, I., Sorgeloos, P., 2000. Enrichment strategies for Artemia using emulsions providing different levels of n-3 highly unsaturated fatty acids. Aquaculture 183, 335-347.

Hoehne, K., 1999. Lipid digestive enzymes in developing larvae of the Atlantic cod (Gadus morhua) and turbot (Scophthalmus maximus). $\mathrm{PhD}$ thesis, Universität Karlsruhe, $111 \mathrm{pp}$.

Iijima, N., Tanaka, S., Ota, Y., 1998. Purification and characterization of bile salt-activated lipase from the hepatopancreas of red sea bream, Pagrus major. Fish Physiol. Biochem. 18, 59-69.

Izquierdo, M.S., Watanabe, T., Takeuchi, T., Arakawa, T., Kitajima, C., 1990. Optimum EFA levels in Artemia to meet the EFA requirements of red sea bream (Pagrus major). In: Takeda, M., Watanabe, T. (Eds.), The Current Status of Fish Nutrition in Aquaculture. Tokyo Univ. Fisheries, Tokyo, pp. 221-232.

Izquierdo, M.S., Socorro, J., Arantzamendi, L., Hernández-Cruz, C.M., 2000. Recent advances in lipid nutrition in fish larvae. Fish Physiol. Biochem. 22, 97-107.

Izquierdo, M.S., Tandler, A., Salhi, M., Kolkovski, S., 2001. Influence of dietary polar lipids' quantity and quality on ingestion and assimilation of labelled fatty acids by larval gilthead seabream. Aquac. Nutr. 7, $153-160$.

Kjørsvik, E., Olsen, Y., Rosenlund, G., Vadstein, O., 1991. Effect of various lipid enrichments in rotifers and the development of early stages in turbot. In: Lavens, P., Sorgeloos, P., Jaspers, E., Ollevier, F. (Eds.), Proceedings of the Fish and Crustacean Larviculture Symposium, Larvi'91. European Aquaculture Society, Special Publication, vol. 15. European Aquaculture Society, Gent, Belgium, pp. 20-22.

Koven, W.M., Henderson, R.J., Sargent, J.R., 1994. Lipid digestion in turbot (Scophthalmus maximus). I: lipid class and fatty acid composition of digesta from different segments of the digestive tract. Fish Physiol. Biochem. 13, 69-79.

Koven, W., Kolkovski, S., Hadas, E., Gamsiz, K., Tandler, A., 2001. Advances in the development of microdiets for gilthead seabream, Sparus aurata: a review. Aquaculture 194, 107-121.

Langdon, C., 2003. Microparticulate types for delivering nutrients to marine fish larvae. Aquaculture 227, 259-275.

Lie, Ø., Lied, E., Lambertsen, G., 1987. Lipid digestion in cod (Gadus morhua). Comp. Biochem. Physiol., B 88, 697-700.

Martoja, R., Martoja-Pierson, M., 1970. Técnicas de Histología Animal. Toray Masson S.A., Barcelona, Spain. 350 pp.

Morais, S., Cahu, C., Zambonino-Infante, J.L., Robin, J., Rønnestad, I., Dinis, M.T., Conceição, L.E.C., 2004a. Dietary TAG source and level affects performance and lipase expression in larval seabass (Dicentrarchus labrax). Lipids 39, 449-458.

Morais, S., Narciso, L., Dores, E., Pousão-Ferreira, P., 2004b. Lipid enrichment for Senegalese sole (Solea senegalensis) larvae: effect on larval growth, survival and fatty acid profile. Aquac. Int. 12, 281-298.

Morais, S., Koven, W., Rønnestad, I., Dinis, M.T., Conceição, L.E.C., 2005 a. Dietary protein: lipid ratio and lipid nature affects fatty acid absorption and metabolism in a teleost larva. Br. J. Nutr. 93, 1-9.

Morais, S., Koven, W., Rønnestad, I., Dinis, M.T., Conceição, L.E.C., 2005b. Dietary protein/lipid ratio affects growth and amino acid and fatty acid absorption and metabolism in Senegalese sole (Solea senegalensis Kaup 1858) larvae. Aquaculture 246, 347-357.

Noaillac-Depeyre, J., Gas, N., 1974. Fat absorption by the enterocytes of the carp (Cyprinus carpio L.). Cell Tissue Res. 155, 353-365.

Olsen, R.E., Myklebust, R., Kaino, T., Ringø, E., 1999. Lipid digestibility and ultrastructural changes in the enterocytes of Arctic char (Salvelinus alpinus L.) fed linseed oil and soybean lecithin. Fish Physiol. Biochem. $21,35-44$.
Olsen, A.I., Attramadal, Y., Reitan, K.I., Olsen, Y., 2000a. Food selection and digestion characteristics of Atlantic halibut (Hippoglossus hippoglossus) larvae fed cultivated prey organisms. Aquaculture 181, 293-310.

Olsen, R.E., Myklebust, R., Ringø, E., Mayhew, T.M., 2000b. The influences of dietary linseed oil and saturated fatty acids on caecal enterocytes in Arctic char (Salvelinus alpinus L.): a quantitative ultrastructural study. Fish Physiol. Biochem. 22, 207-216.

Olsen, R.E., Dragnes, B.T., Myklebust, R., Ringø, E., 2003. Effect of soybean oil and soybean lecithin on intestinal lipid composition and lipid droplet accumulation of rainbow trout, Oncorhynchus mykiss Walbaum. Fish Physiol. Biochem. 29, 181-192.

Oxley, A., Torstensen, B.E., Rustan, A.C., Olsen, R.E., 2005. Enzyme activities of intestinal triacylglycerol and phosphatidylcholine biosynthesis in Atlantic salmon (Salmo salar L.). Comp. Biochem. Physiol., B 141, 77-87.

Pérez, J.A., Rodríguez, C., Henderson, R.J., 1999. The uptake and esterification of radiolabelled fatty acids by enterocytes isolated from rainbow trout (Oncorhynchus mykiss). Fish Physiol. Biochem. 20, 125-134.

Pousão-Ferreira, P., Morais, S., Dores, E., Narciso, L., 1999. Eggs of gilthead seabream Sparus aurata L. as a potential enrichment product of Brachionus sp. in the larval rearing of gilthead seabream Sparus aurata L. Aquac. Res. 30, 751-758.

Rainuzzo, J.R., Reitan, K.I., Olsen, Y., 1997. The significance of lipids at early stages of marine fish: a review. Aquaculture 155, 103-115.

Ribeiro, L., Zambonino-Infante, J.L., Cahu, C., Dinis, M.T., 1999. Digestive enzymes profile of Solea senegalensis post larvae fed Artemia and a compound diet. Fish Physiol. Biochem. 27, 61-69.

Rodríguez, C., Pérez, J.A., Lorenzo, A., Izquierdo, M.S., Cejas, J.R., 1994. n-3 HUFA requirements of larval gilthead seabream Sparus aurata when using high levels of eicosapentaenoic acid. Comp. Biochem. Physiol., A 107, 693-698.

Rodríguez, C., Pérez, J.A., Izquierdo, M.S., Cejas, J.R., Bolaños, A., Lorenzo, A., 1996. Improvement of the nutritional value of rotifers by varying the type and concentration of oil and the enrichment period. Aquaculture 147, 93-105.

Rutter, W.J., 1967. Protein determinations in embryos. In: Wilt, F.H., Wessels, N.K. (Eds.), Methods in Developmental Biology. Academic Press, NY, pp. 671-684.

Rønnestad, I., Rojas-García, C.R., Tonheim, S.K., Conceição, L.E.C., 2001. In vivo studies of digestion and nutrient assimilation in marine fish larvae. Aquaculture 201, 161-175.

Salhi, M., Kolkovski, S., Izquierdo, M.S., Tandler, A., 1995. Inclusion of lecithin and polar or neutral lipids high in n-3 HUFA in microdiets for gilthead seabream Sparus aurata larvae. In: Lavens, P., Jaspers, E., Roelants, I. (Eds.), Proceedings of the Fish and Shellfish Larviculture Symposium - Larvi'95. European Aquaculture Society, Special Publication, vol. 24. European Aquaculture Society, Gent, Belgium, pp. 184-187.

Salhi, M., Izquierdo, M.S., Hernandez-Cruz, C.M., Socorro, J., FernandezPalacios, H., 1997. The improved incorporation of polyunsaturated fatty acids and changes in liver structure in larval gilthead seabream fed on microdiets. J. Fish Biol. 51, 869-879.

Salhi, M., Hernandez-Cruz, C.M., Bessonart, M., Izquierdo, M.S., FernandezPalacios, H., 1999. Effect of different dietary polar lipid levels and different n-3 HUFA content in polar lipids on gut and liver histological structure of gilthead seabream Sparus aurata larvae. Aquaculture 179, 253-263.

Sargent, J.R., McEvoy, L.A., Bell, J.G., 1997. Requirements, presentation and sources of polynsaturated fatty acids in marine fish larval feeds. Aquaculture $155,117-128$.

Sargent, J.R., McEvoy, L.A., Estevez, A., Bell, G., Bell, M., Henderson, J., Tocher, D., 1999. Lipid nutrition of marine fish during early development: current status and future directions. Aquaculture 179, 217-229.

Sire, M.-F., Vernier, J.-M., 1981. Étude ultrastructurale de la synthèse de chylomicrons au cours de l'absorption intestinale des lipides chez la Truite. Influence de la nature des acides gras ingérés. Biol. Cellulaire 40, 47-62. 
Sire, M.-F., Lutton, C., Vernier, J.-M., 1981. New views on intestinal absorption of lipids in teleostean fishes: an ultrastructural and biochemical study in the rainbow trout. J. Lipid Res. 22, 81-94.

Tseng, H.C., Grendell, J.H., Rothman, S.S., 1982. Food, duodenal extracts, and enzyme secretion by the pancreas. Am. J. Physiol. 243, G304-G312.

van Greevenbroek, M.M.J., Voorhout, W.F., Erkelens, D.W., van Meer, G., de Bruin, T.W.A., 1995. Palmitic acid and linoleic acid metabolism in Caco-2 cells: different triglyceride synthesis and lipoprotein secretion. J. Lipid Res. $36,13-24$.
Van Stappen, G., 1996. Use of cysts. In: Lavens, P., Sorgeloos, P. (Eds.), Manual on the production and use of live food for aquaculture. . FAO Fisheries Technical Paper, vol. 361. Food and Agriculture Organization of the United Nations (FAO), Rome, pp. 107-136.

Yúfera, M., Kolkovski, S., Fernández-Díaz, C., Rinchard, J., Lee, K.J., Dabrowski, K., 2003. Delivering bioactive compounds to fish larvae using microencapsulated diets. Aquaculture 227, 277-291.

Zar, J.H., 1996. Biostatistical Analysis. Prentice Hall International, NJ, USA. $662 \mathrm{pp}$. 